\title{
Managing Transformers Risk through Failure Codification
}

Abdullah Mohammed Al Qabtan ${ }^{1}$, Mohammed Said Dad Allah AlZadjali ${ }^{1}$, Omran Omar AL Balushi ${ }^{1}$ Oman Electrical Transmission Company, Asset Performance Management Department, Muscat, Oman P.O box 1389 Al Khoudh P.C 132

E-mail: abdullah.alqubtan@omangrid.com

\begin{abstract}
The fast development and expansion of any service organizations which followed by increases in the asset numbers that's need to have a proper maintenance strategy which should be cost effective. The aim of any strategy is to have a plan that contribute to improve asset performance by reducing downtime of asset failures.

The aim of this paper is to set plan that determine the processes of creating failure code that can create a library of failure modes with its consequences and risk. This allow service provider to quickly understand the problem and any action that can be taken which have already proven by failure mode effect analysis. Also it's identify most of the functional failures that might happened in the critical asset in the OETC's network. In this study the transformer asset class was taken into the consideration for full failure mood and fault tree analysis.

Defining failure codes can give specific instructions to complete a task to reduce the main time to wait in any failure from the total main time to repair, and any smiler failure mode from other assets the corrective action will remain consistent.

The selective processes of creating a failure code give the organization a more holistic view of transformers risk which will be used to improve maintenance strategy by integrate those codes into work order system like CMMS.

Index Terms - OLCM: On line condition monitoring, OETC: Oman Electricity Transmission Company, CMMS: computerized Maintenance Management System, RCM: Reliability Centered Maintenance, RCA: Root Cause Analysis, FTA: Fault Tree Analysis
\end{abstract}

\section{INTRODUCTION}

Asset Performance Management shall constantly endeavor to monitor and continuously improve the performance of the asset management system in order to ensure the effectiveness and efficiency of the transmission system in line with the Asset Management Objective. This process aims to provide a philosophy concerning the way to identify the source of failures and to change in working practices, values, relationships and culture in the company by focusing on how to manage failures rather than to select desired proactive tasks. Usually implemented when the systems fail to do what user want form the asset to do, but also aimed to improving the effectiveness of equipment by eliminating problems once and for all, by sustaining a level of asset care and good practice that prevent deterioration.

The process start up with a fault tree analysis (FTA). FTA is a logical diagram which shows the relation between system failure, and a specific undesirable events in the system as well as failures of the components of the system. The undesirable event constitutes the top event of the tree and the different component failures constitute the basic event of the tree where that must end with a desired outcome, and this needs to have a right process to manage the deliverables of proactive tasks.

\section{FAILURE CODIFICATION APPROACH}

With this emphasis on preserving what the RCA wants, Moubray [1] defines RCM as: "A process used to determine what must be done to ensure that any physical asset continues to do what its users want it to do in its present operating context." RCM approach considers seven questions as a starting point of the process.

1- What are the function and associated performance standards of asset in its present operating context?

2- In what ways does it fail to fulfil its functions?

The failure behavior of the selected assets should be identified by analyzing them under FTA approach that gives an overview of the subsystem failure contribution to the top event.

3- What causes each functional failure?

The common failure modes that may affect asset performance capability

4- What happen when each failure occur?

Understanding the effect of each failure modes will helps to evaluate the consequence of risk. This description identifying the level of severity and how could effect on the objectives of corporate business performance.

5- In what way does each failure matter?

The process focusing on managing the consequences of failure of each failure mode which is categorized as the followings:

-Hidden failure consequences: which has no direct impact to the operating crew under normal circumstances, but it may has serious/ catastrophic consequences, and most of those failure may happened in electrical system where, the deterioration of normal current are many and the source of problem are deferent as well.

- Safety and Environment Consequences: these are evident failures; the majority of this consequence can be defined on the risk assessment task, in order to know if this kind of risk can kill someone or breach any environmental regulations. 
- Operational Consequences: these are evident failures; shutdown and blackout are the most critical time in the transmission line services, and the impact of blackout in long term can be reflected on the management quality of asset performance. These include lost production, increased operating costs, degradation in product quality, poor customer service, etc.

- Non- Operational Consequences: this kind of consequences caused by evident failure mode which has neither adversely effect on operation capability nor safety \& environment, where their impacts on cost of repair only.

In so doing, those categories emphasize firstly on safety and environment issues, and then it focuses on how to manage failures rather than to select desired proactive tasks.

Process to Evaluate the Consequences of Failure:

Process to Evaluate the Consequences of Failure:

\begin{tabular}{|c|c|c|c|c|c|}
\hline Evident Failure & Yes & $\begin{array}{c}\text { Safety or } \\
\text { Environment Issues }\end{array}$ & No & $\begin{array}{c}\text { Operational } \\
\text { Consequences }\end{array}$ & No \\
\hline No & & Yes & & Yes & \\
\hline $\begin{array}{l}\text { Hidden failures } \\
\text { on their own do } \\
\text { not have any } \\
\text { direct } \\
\text { consequences }(\mathrm{H})\end{array}$ & & $\begin{array}{l}\text { Failures that can } \\
\text { kill someone or } \\
\text { breach any } \\
\text { environmental } \\
\text { regulations }(\mathrm{S} / \mathrm{E})\end{array}$ & & $\begin{array}{l}\text { Failures that can kill } \\
\text { someone or breach } \\
\text { any environmental } \\
\text { regulations }(\mathrm{O})\end{array}$ & $\begin{array}{l}\text { Non- Operational } \\
\text { Consequences } \\
\text { which only affect } \\
\text { direct cost of repair } \\
\text { (N) }\end{array}$ \\
\hline
\end{tabular}

6. What can be done to predict or prevent each failure?

The Proactive Task Selection Process defined in Fig. 1 below.

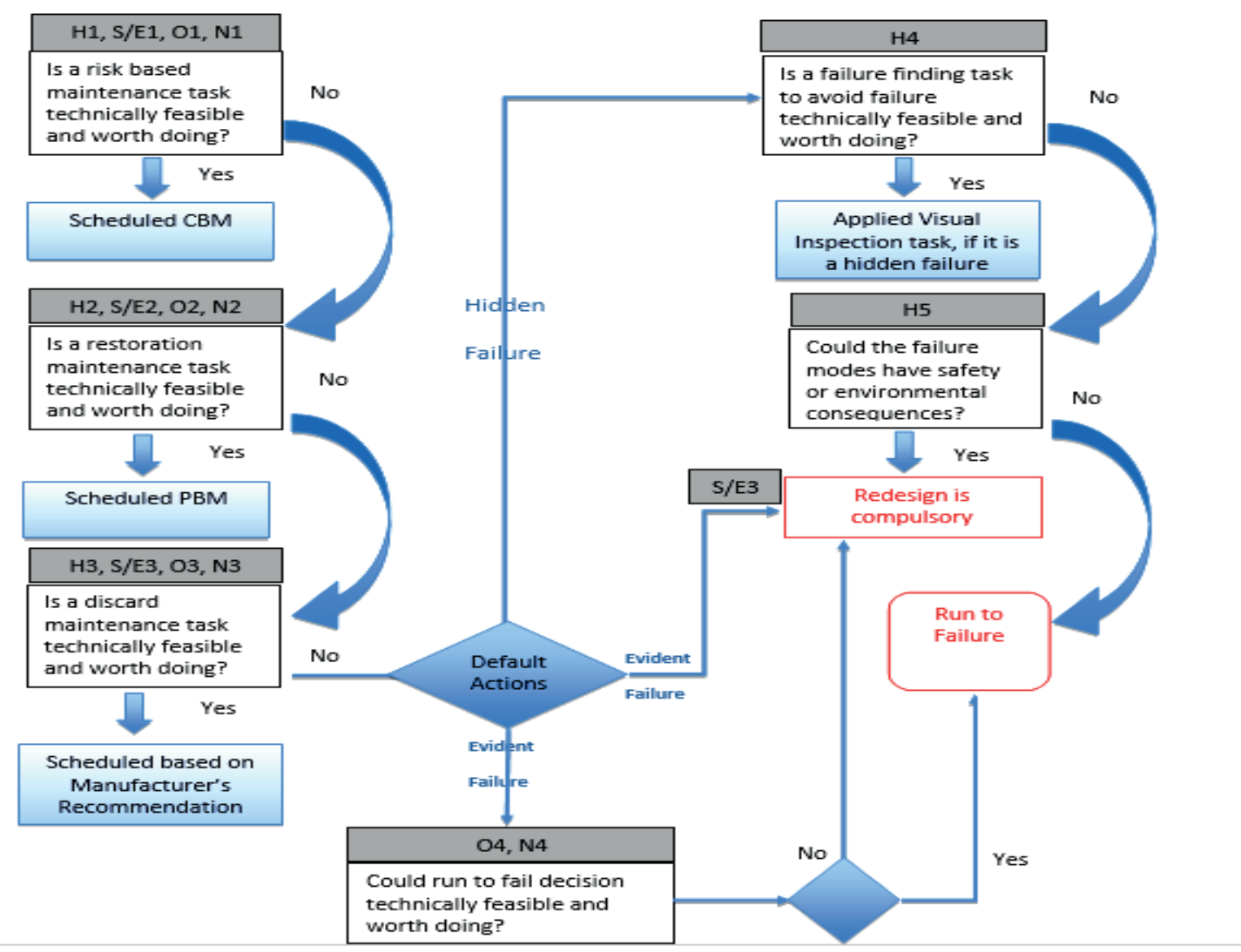

Figure 1: Proactive Task Selection Process 
7. What should be done if a suitable proactive task cannot be found?

Default tasks known as the tasks that includes run- to failure, failure finding and redesign. In other hand, the process advice to go through reactive tasks and that may eliminate the effects of failures once it occur.

\section{TRANSFORMER FMEA}

Power transformers in the transmission system are one of the main assets that can effect on the network reliability if they fail to do its operation. According to a described FTA of Transformer that is illustrated on the below diagram Fig. 2, each subsystem functions of the main asset class like transformer's oil should be identified clearly. Furthermore, transformer's oil plays as an insulation factor and it may fail due to water ingress, oil poor quality and oil contamination and also, the other purpose of transformer's oil is to maintain the dissipated heat into stabilized level, where its failure correlated with cooling system failures and due to deterioration of auxiliary's performance such as breathing system.

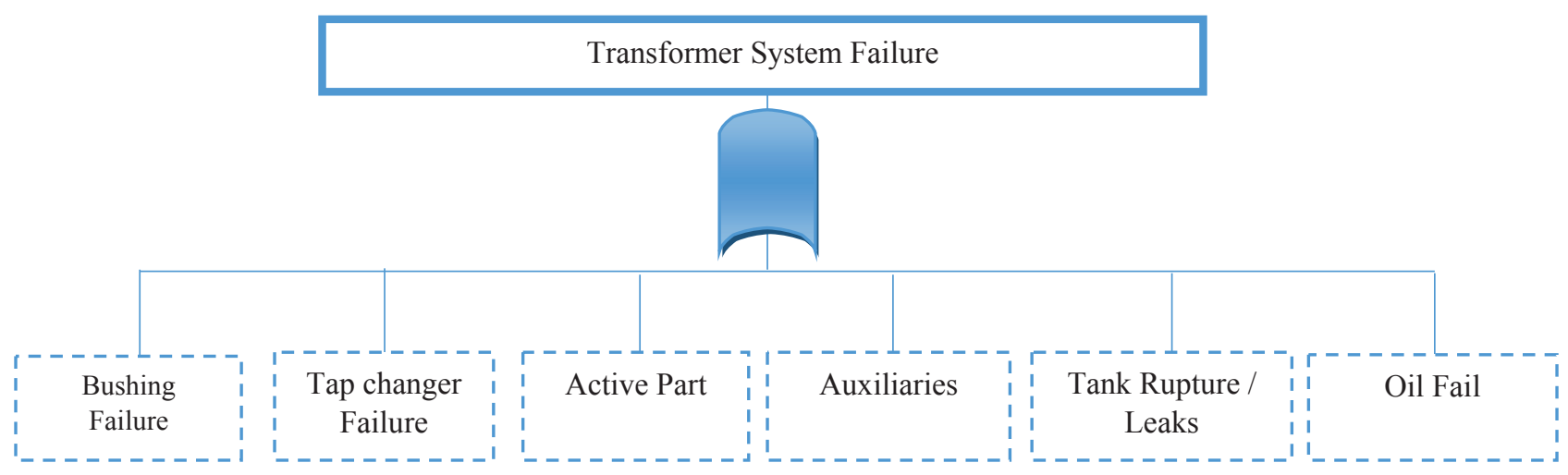

Figure 2: Transformer Fault Tree

According to above Fig. 2, each subsystem events should be analyzed throughout consequence evaluation in conjunction with the required proactive task that is shown in Fig. 1, and each number in Fig. $1(1,2,3,4,5)$ refer to the maintenance category $(\mathrm{CBM}, \mathrm{PBM}, . .$.$) that are linked with described consequence of that event. Furthermore, to create$ a failure code each subsystem will be considered as a separate function (F) and defined with a unique number, and its functional failures (FF) that are defined in FTA will take place as an alphabet later. Each functional failure has its own failure modes (FM) that again numbered with a unique number and all similar failure modes of different functional failures will be described with same number as they have same nature of failure but cause different failure. Table .1 below illustrate failure mode effect analyses of power transformer.

TABLE I. POWER TRANSFORMER (FMEA)

\begin{tabular}{|c|c|c|c|c|c|}
\hline & Function & \multicolumn{2}{|r|}{ Function Failure } & \multicolumn{2}{|c|}{ Failure Mode/Cause } \\
\hline \multirow{9}{*}{1} & \multirow{9}{*}{ Bushing } & \multirow{3}{*}{ A } & \multirow{3}{*}{ Bushing Structure } & 1 & Gasket Fail \\
\hline & & & & 2 & Housing Fail \\
\hline & & & & 3 & Fitting Fail \\
\hline & & $\mathrm{B}$ & Conductor/Lead & 4 & Connection/Brazing \\
\hline & & \multirow{5}{*}{$\mathrm{C}$} & \multirow{5}{*}{ Insulation Material } & 5 & Paper Deterioration \\
\hline & & & & 6 & Lead Fail \\
\hline & & & & 7 & Oil contamination \\
\hline & & & & 8 & Aluminum foil Fail \\
\hline & & & & 9 & Test Tap \\
\hline \multirow{8}{*}{2} & \multirow{8}{*}{ Tap changer } & \multirow{5}{*}{ A } & \multirow{5}{*}{ Drive Mechanism Fails } & 10 & Motor Fails \\
\hline & & & & 11 & Gear Box and shaft Fails \\
\hline & & & & 12 & Limit Switch Fails \\
\hline & & & & 13 & Manual Operation Fail \\
\hline & & & & 14 & Power Supply Fail \\
\hline & & $\mathrm{B}$ & Tap Selection Switch & 15 & Contacts Wear \\
\hline & & $\mathrm{C}$ & Diverter Switch Fails & 16 & Contacts Failure \\
\hline & & $\mathrm{C}$ & Diverter switch rans & 17 & Resistor fail \\
\hline
\end{tabular}




\begin{tabular}{|c|c|c|c|c|c|}
\hline & & \multirow{2}{*}{$\mathrm{D}$} & \multirow{2}{*}{ Tap Changer Oil } & 7 & Oil Contamination \\
\hline & & & & 18 & Oil Level low \\
\hline & & \multirow{3}{*}{$\mathrm{E}$} & \multirow{3}{*}{ OLTC Compartment } & 19 & Bucholz Relay fail \\
\hline & & & & 20 & PRD Fail \\
\hline & & & & 21 & Fiber Glass Cylinder \\
\hline \multirow{11}{*}{3} & \multirow{11}{*}{ Tank } & \multirow{3}{*}{ A } & \multirow{3}{*}{ Bucholz Relay fail } & 22 & Float Fail \\
\hline & & & & 23 & Switch Disconnected \\
\hline & & & & 24 & Bucholz Valve Fail \\
\hline & & \multirow{8}{*}{$\mathrm{C}$} & \multirow{3}{*}{ PRD Fail } & 25 & Disk Fail \\
\hline & & & & 26 & Spring Fail \\
\hline & & & & 23 & Switch Disconnected \\
\hline & & & \multirow{5}{*}{ Covers \& Main Body } & 1 & Gasket Fail \\
\hline & & & & 27 & Corrosion \\
\hline & & & & 28 & Lack of Maintenance \\
\hline & & & & 80 & Environmental Stress \\
\hline & & & & 29 & Physical Damage \\
\hline \multirow{6}{*}{4} & \multirow{6}{*}{ Oil } & \multirow{2}{*}{ A } & \multirow{2}{*}{ Prticles in the Oil } & 30 & Overheated \\
\hline & & & & 31 & Aging \\
\hline & & $\mathrm{B}$ & Poor Oil Quality & 32 & Poor Oil Quality \\
\hline & & \multirow{3}{*}{$\mathrm{C}$} & \multirow{3}{*}{ Water Ingress } & 33 & Oil Leak \\
\hline & & & & 31 & Aging \\
\hline & & & & 34 & Breather Fail \\
\hline \multirow{11}{*}{5} & \multirow{11}{*}{ Auxiliary } & \multirow{3}{*}{ A } & \multirow{3}{*}{ Cooling System } & 35 & Fan Fails \\
\hline & & & & 36 & Pump Fails \\
\hline & & & & 37 & Radiator Fails \\
\hline & & \multirow{5}{*}{$\mathrm{B}$} & \multirow{5}{*}{ Breathing System } & 38 & Supply Fail \\
\hline & & & & 39 & Silica gel Fail \\
\hline & & & & 40 & Heater Fail \\
\hline & & & & 41 & Oil Cap Fail \\
\hline & & & & 42 & Conservator Tank Fail \\
\hline & & & & 43 & Sensors Fail \\
\hline & & $\mathrm{C}$ & Monitoring System & 44 & Analyzer Equipment Fail \\
\hline & & & & 45 & Carrier Gas Cylinder Fail \\
\hline & & & & 6 & Lead Fail \\
\hline & & A & Winding & 46 & Insulation Paper (Celleulose) \\
\hline 6 & ACTIVE PART & & & 47 & Displacement of Core steel \\
\hline & & $\mathrm{B}$ & Core & 29 & Physical Damage \\
\hline & & & & 48 & DC Magnetization \\
\hline
\end{tabular}

\section{MANAGEMENT RISK of TRANSFORMER FAILURE AND CREATING FAILURE CODE}

The risk assessment framework defined within OETC based on the ratio between likelihood and consequences (critical analysis). Contribution of the subsystems failure to the major failure should be taken into account. Hence, risk assessment would be estimated according to asset management risk framework that covers expected load no longer meeting security standard, expected load interrupted, expected asset loading, safety, environmental and financial impact. The total score of the classified risk consequences that is shown in appendix- A will be escalated or deescalated according to the probability of failure (likelihood) which was identified from the past incidents and then simulated with corporate risk register to understand the impact of those failure on the whole business. This correlation gives asset management engineers the rational basis to decide the required solutions, and the right maintenance actions to be performed. Also, managing system failures against risk, will help to categorizing the required subsystem spares according to risk level, and to set a contingency plan of backup spares limitation by defining maximum backup spares from the minimum one within the inventory list. Therefore, failure codes could be vary according to the current risk situations which will help also the service provider to understand the nature of failure and the required action complete the work order and to close the incidents once it happened. Fig. 3 shows risk scoring practice within OETC and the total score will be converted into corporate risk level. 


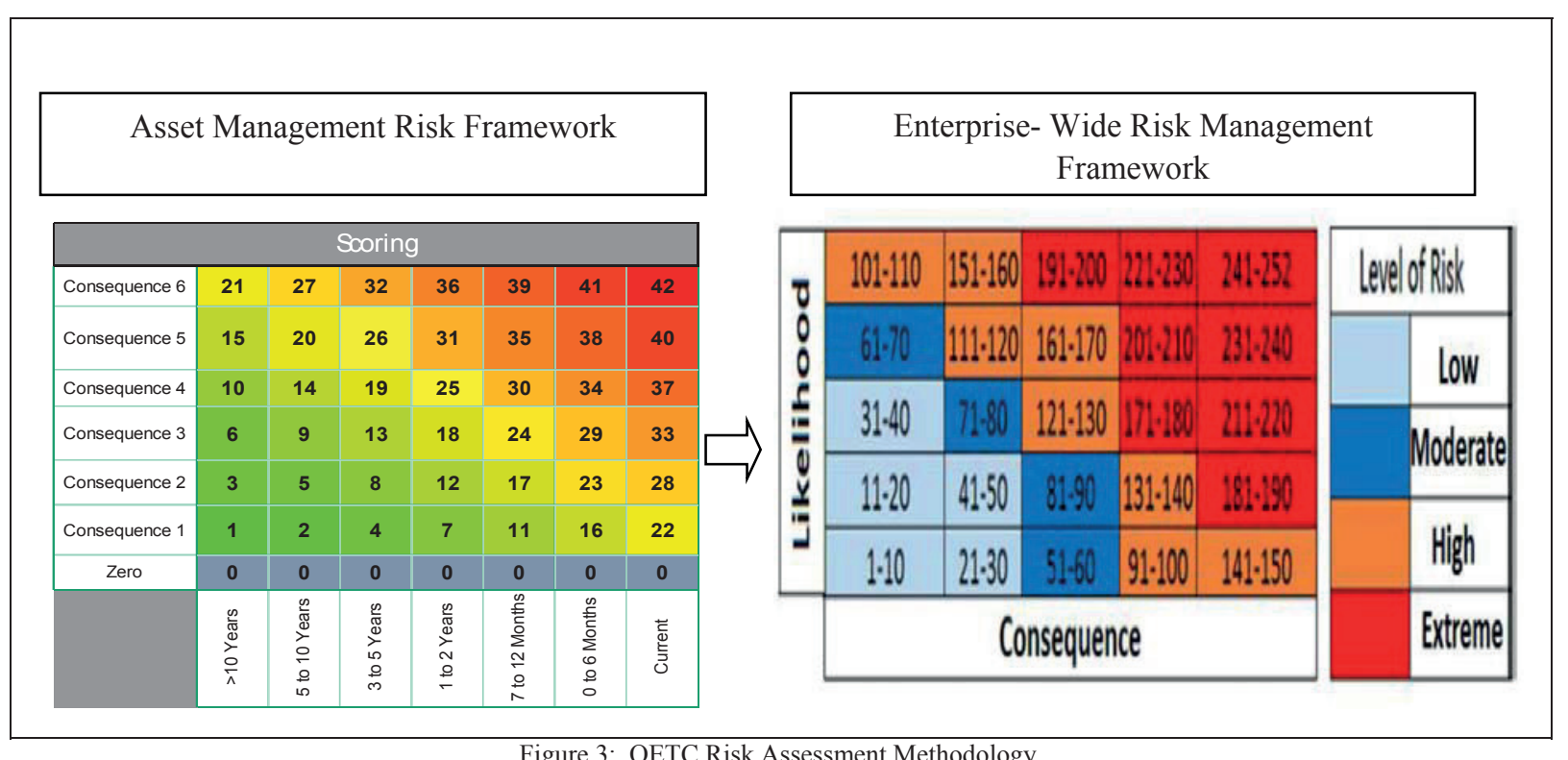

Figure 3: OETC Risk Assessment Methodology.

After defining transformer FMEA, each failure mode with the specific functional failure is linked with consequence code reference $(\mathrm{H}, \mathrm{S} / \mathrm{E}, \mathrm{O}, \mathrm{N})$, and with suitable proactive task number then with the defined risk level for each failure. Therefore, the failure code of transformer $(\mathrm{TX})$ bushing $(\mathrm{Bu})$ failure is: TX, Bu, 1A1, S/E1, Low that defined in the Table II below.

TABLE II. POWER TRANSFORMER CODIFICATION METHODOLOGY

\begin{tabular}{|c|c|c|c|c|c|c|c|c|c|c|c|}
\hline \multicolumn{2}{|c|}{ Equipment/Identifier } & \multicolumn{3}{|c|}{$\begin{array}{c}\text { FMEA } \\
\text { Reference }\end{array}$} & \multirow[b]{2}{*}{$\begin{array}{l}\text { Consequence } \\
\text { Evaluation }\end{array}$} & \multicolumn{3}{|c|}{$\begin{array}{c}\text { Technical } \\
\text { Feasibility } \\
\text { Level }\end{array}$} & \multicolumn{2}{|c|}{$\begin{array}{c}\text { Default } \\
\text { Task }\end{array}$} & Risk Level \\
\hline System & Subsystem & $\mathrm{F}$ & $\mathrm{FF}$ & FM & & 1 & 2 & 3 & 4 & 5 & $\begin{array}{l}\text { (Expected load no longer } \\
\text { meeting security standard, } \\
\text { expected load interrupted, } \\
\text { expected asset loading, } \\
\text { safety, environmental, } \\
\text { financial impact) *Appendix- A }\end{array}$ \\
\hline $\mathrm{TX}$ & $\mathrm{Bu}$ & 1 & A & 1 & $\mathrm{~S} / \mathrm{E}$ & $\square$ & & & & & $\begin{array}{c}(2,5,5,14,2,5)=33 \\
\text { Low }\end{array}$ \\
\hline
\end{tabular}

From Table I, table. II and according to RCM approach, fifty five kind of failure code have been created for the transformer failure. All the created transformer failure code have been started with TX, where TX was selected as a reference symbol of the transformer asset class.

Nonetheless, the study not conducted only to create a failure code, but also gives a hypothesis of failure behaviors in the network by analyzing each failure with its consequence and gives an overview of the risk level with desired maintenance plan, which create an approach of risk based maintenance strategy that focusing on selecting the right action upon the status of risk against cost under the point view of technically feasible and worth doing. It has been observed that the total transformer failure that could be monitored around 49 failures out of 55 failures and the remaining 6 failures, where 4 of them will be controlled under maintenance restoration task and the other 2 will be taken under default actions. Therefore the total detectable failure around 89.09\% and the non-detectable failure around $10.91 \%$. From another angle, according to risk evaluation for each failure, it has been noted that the total low risk around $76.36 \%$, while moderate risk level covers $21.82 \%$ from the total risk and only $1.82 \%$ considered as a high risk level. No extreme risk has been considered according to the records of risk management register. Consequently, the total debatable failure with risk level will be as the following: 37 failures as a low risk, 11 failures moderate risk and 1 failure as a high risk. From this standpoint, asset management launch a project to establish and implement a continuous On-Line Condition Monitoring (OLCM) system for OETC's network assets. It was found that the probabilistic tangible benefits are derived from the failure code model, where the failure rate of transformers is $0.5 \%$ [2] for average age of OETC transformers according to CIGRE Guide 248. According to the reliability centered maintenance recommendations which describe the desirable of condition monitoring implementation against other maintenance 
tasks, $89.09 \%$ of $0.5 \%$ of probable failure can be detected by condition monitoring activities. Hence the probabilistic detectable failure rate by condition monitoring task is around 0.044 . If the capital cost of power transformer of 750 MVA is considered about 1.5 million Omani Rials, than the total probabilistic detectable tangible benefits around 66,000 Omani Rials. Such studies could be implemented taken failure code model as a reference which could be vary from utility to the other, according to their experience and to the type of risk appetite.

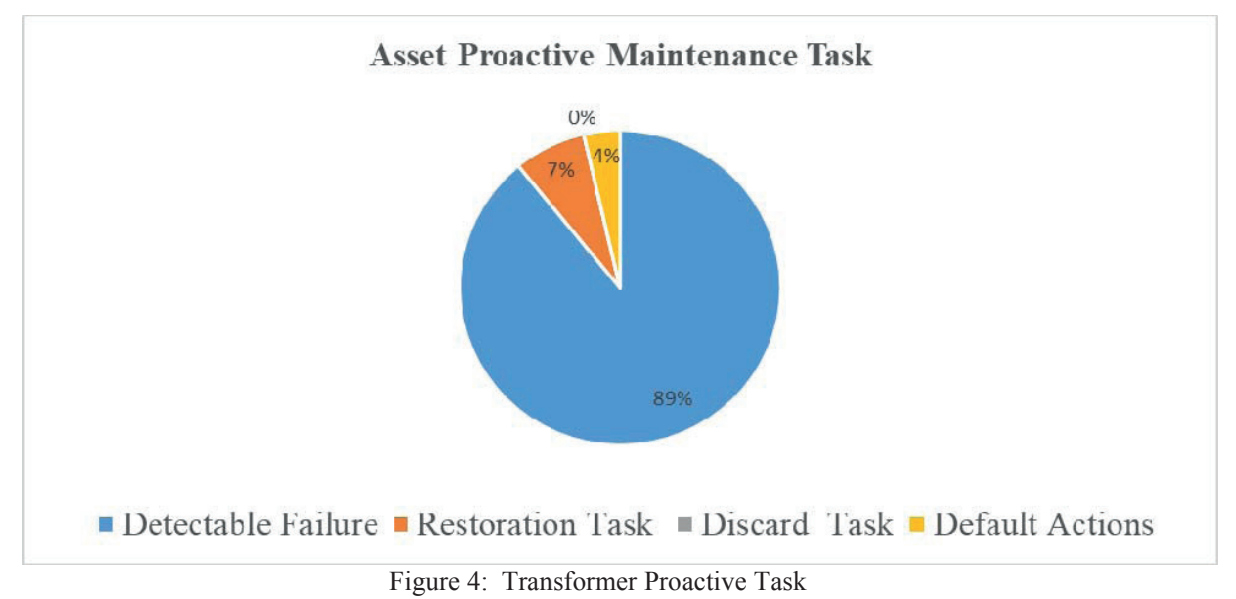

\section{FAILURE CODE SYSTEM MODEL AND CMMS INTEGRATION}

Asset Management, introduced a failure codification management system, the codes installed on OETC servers and it provides full support that centralizing the information within the CMMS system. This vision needs many stages and tools that can be shortly defined as a Failure Codification Model that has a closed framework process to enhance risk management system and to provide modern analytic strategy. To cope with strategic model, failure code shall control the systematic approach in terms of incident data management, required maintenance over risk, performance system study, maintenance strategy and asset performance management.

The output and benefits of implementing failure codification model are addressed below:

- Centralize failure code within CMMS system

- Governance data management system

- Avoid discrepancy between failure and right proactive action

- Organizing the circulation of failure risk review process

- Secure and document incident register with failure code and then align it with risk status

- Adhere service provider engineer to follow the process of maintenance and failure codification review process

- $\quad$ Referencing failure code and asset sock over age profile

- Helps to analyze asset system failure.

- Enhanced regulatory compliance and reporting

In CMMS, failures codification is loaded in term of sets. Each set consist of failure code, cause code and resolution code. In other words, table I above is transformed into CMMS to create failure codifications. Moreover, table III below illustrates an example of failure codification. 


\begin{tabular}{|c|c|c|c|c|c|c|c|}
\hline \multicolumn{2}{|c|}{ Failure } & \multicolumn{2}{c|}{ Cause } & \multicolumn{2}{c|}{ Resolution } & \multicolumn{2}{c|}{ Failure set } \\
\hline Code & Description & Code & Description & Code & Description & Code & Description \\
\hline F023 & Bushing_Structure_1-A & C001 & $\begin{array}{c}\text { Gasket } \\
\text { Fail-1 }\end{array}$ & R008 & $\begin{array}{c}\text { Scheduled CBM- } \\
\text { S/E1 }\end{array}$ & Transformer_FC & $\begin{array}{c}\text { Transformers } \\
\text { Failure codes }\end{array}$ \\
\hline
\end{tabular}

Each failure code starts with " $F$ " and three digit numbers indicating a unique failure code, similarly, cause codes starts with " $C$ " and resolution codes starts with " $R$ ".

Failure codes of table I are programmed in CMMS in a systematic way, such that whenever an engineer chooses certain failure, system limits all causes to that failure. Correspondingly, it limits all resolutions based on the chosen cause of the failure.

Failure analysis section in CMMS supports engineers in following up historical failure data, modifying or adding new failure codes and it shows the hierarchy of all failure codes which displays the linkage of all failure, cause and resolution. Fig. 5 below shows failure analysis section in CMMS, where engineer can search for any previous failure stored in CMMS.

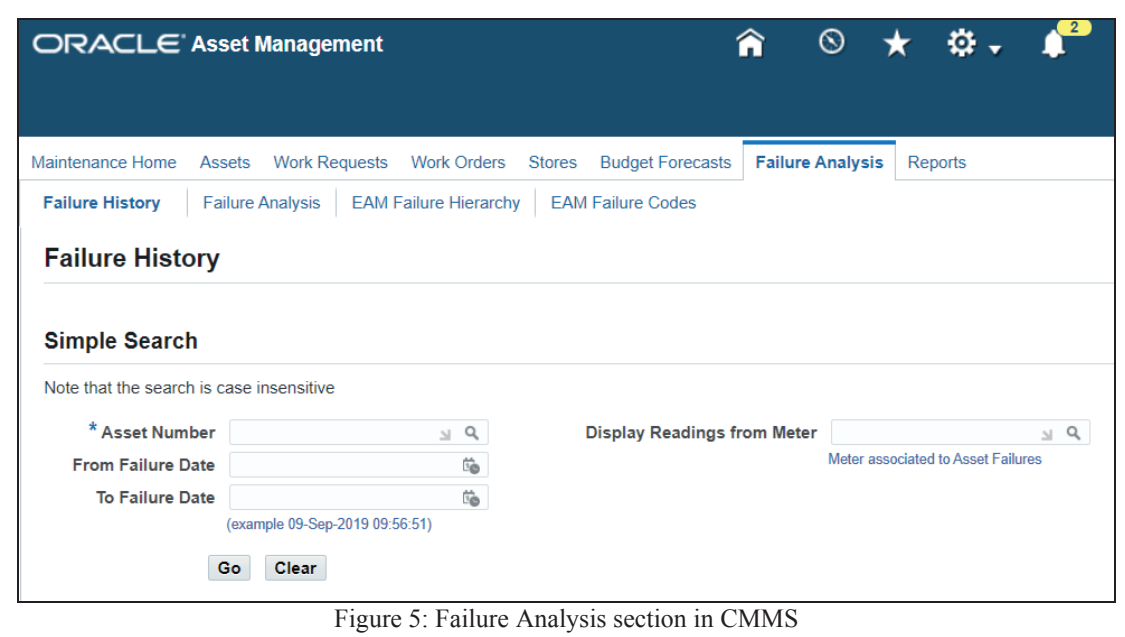

Failure sets gather all failures, causes and resolution in one code based on asset class, which make it easier for an engineer to record or search for a failure in certain asset group.

Another feature of failure codes in CMMS that it is linked with work orders. Any failure occurs while executing a work in the site can be recorded to that particular work order. Moreover, this linkage between failure codes and work orders will keep a historical record of all failures in each asset, which will supports the management in taking decisions.

\section{CONCLUSION}

There is a need for raising the quality level of maintainability with improved RCM procedure and guidelines from failure code. With respect to the identified issues, the paper is recommends the followings:

- Review and improve the present maintenance against risk

- Create a unique failure code and that has to be utilized within company documentations

- Increase general awareness of the risk level and prepare proper mitigation / contingency plan

The proactive tasks from RCM have been designed to fit risk impacts under consideration of cost effective maintenance. Also, any maintenance program has to be scheduled to meet risk mitigation plan and to ensure the availability of spare parts when it's required. The importance of availability of spare parts is to maintain and to optimize spare parts inventory to support reliability and maintainability objectives. Strategic spare parts requirement has to be aligned with failure code to ensure best availability level and to meet security standard requirements.

OETC implement this concept on the other critical assets like: transformer, switchgear, protection system, overhead lines and underground cables. All critical assets have now a unique failure code that give the service provider a full picture of the failures and their mitigation actions. Also, this model document the failures with the 
proposed codes that are linked with risk management process which will be reviewed quarterly basis once there extreme and high risk.

\section{REFERENCES}

[1] Moubray.J., 1992. Reliability Centered Maintenance. 2th. USA: Industrial Press Inc.

[2] Cigre Guid 248 Power Transformer Failure Rate change by age of unit. 


\section{APPENDIX A}

Expected Load no Longer meeting Security

Standard

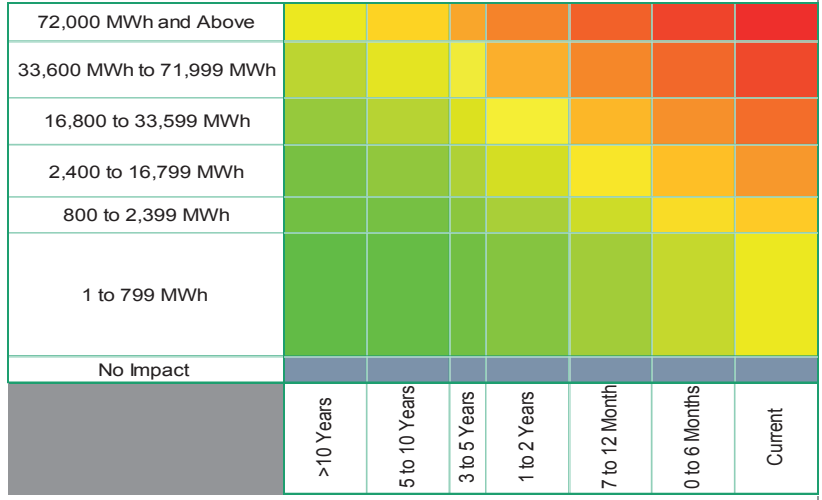

\section{Expected Asset Loading}

$\%$

NS

Expected loading of related assets resulting from asset event, load growth or lack of investment

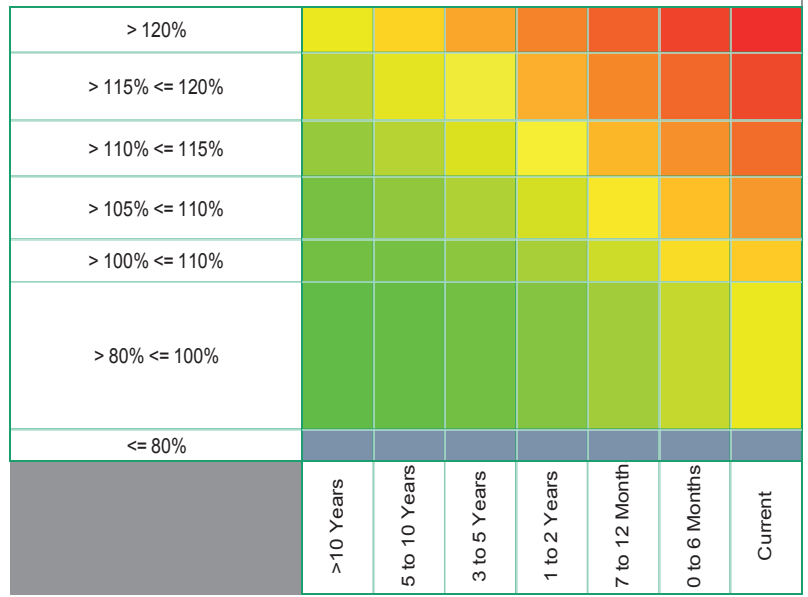

Environmental Impact

Its or $\mathrm{kg}$

NS

Expected environmental impact resulting from asset event

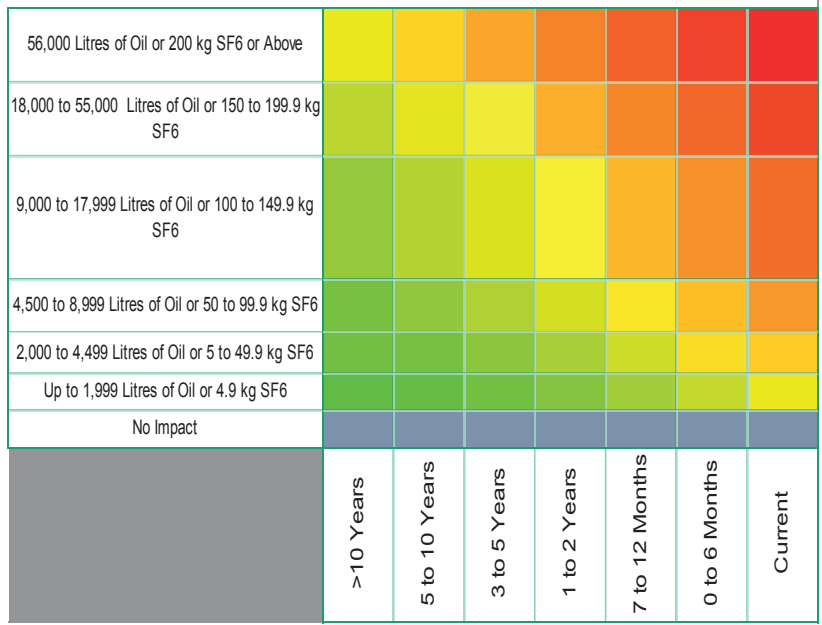

Expected Load Interrupted

MWh

NS The expected amount of load (in MW) interrupted for
implementation of the mitigating action (in hours)

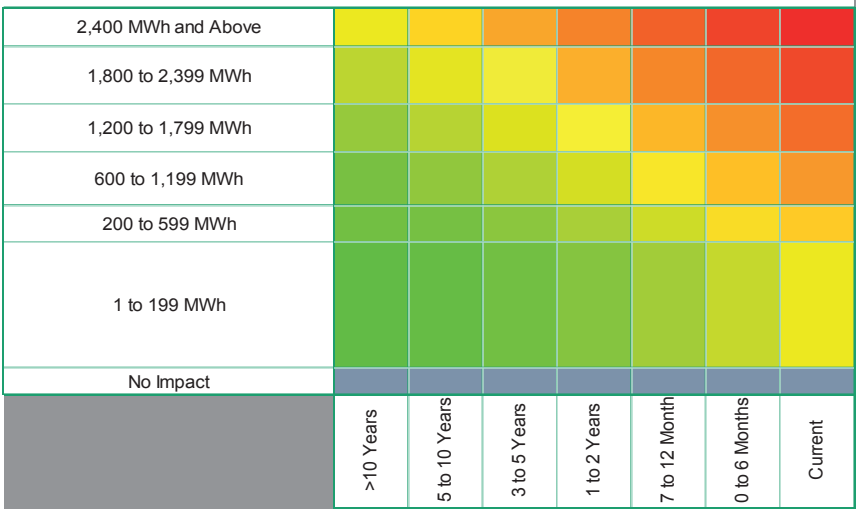

Safety

Scale

NS

Expected safety impact resulting from asset event

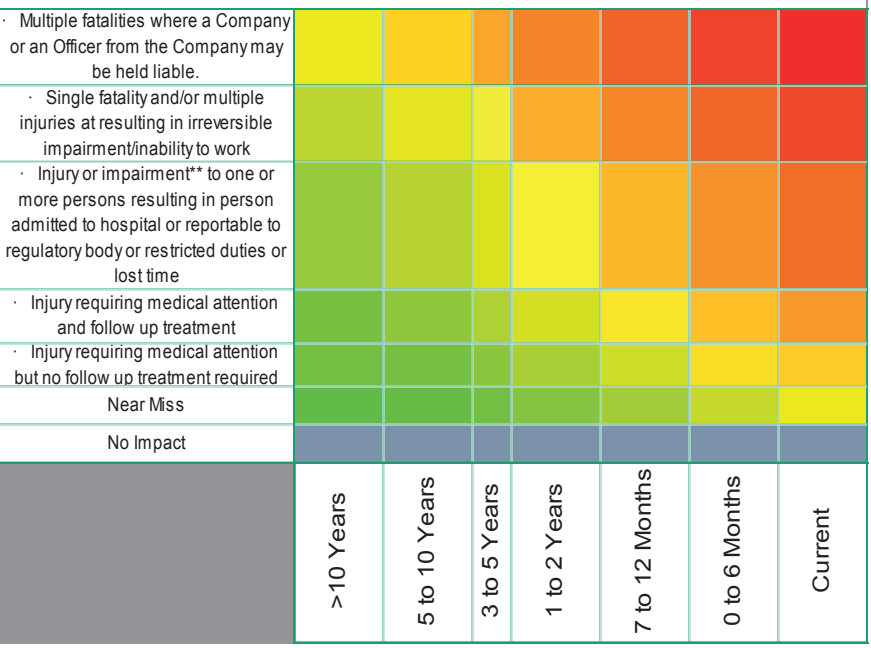

Finance

OMR

NS

Expected direct financial impact resulting from asset event (excluding lost revenue)

\begin{tabular}{|c|c|c|c|c|c|c|c|}
\hline 250,000 OMR or Above & & & & & & & \\
\hline 100,000 to 249,999 OMR & & & & & & & \\
\hline 50,000 to 99,999 OMR & & & & & & & \\
\hline 25,000 to $49,999 \mathrm{OMR}$ & & & & & & & \\
\hline 10,000 to 24,999 OMR & & & & & & & \\
\hline 1 to 9,999 OMR & & & & & & & \\
\hline No Impact & & & & & & & \\
\hline & 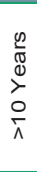 & $\begin{array}{l}\frac{0}{\mathbb{N}} \\
\stackrel{0}{2} \\
0 \\
\frac{0}{0} \\
\frac{0}{0}\end{array}$ & $\begin{array}{l}\frac{n}{\pi} \\
\frac{0}{2} \\
i \\
0 \\
0 \\
m\end{array}$ & 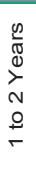 & 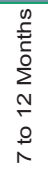 & $\begin{array}{l}0 \\
\stackrel{0}{1} \\
\sum_{0}^{0} \\
0 \\
0 \\
0\end{array}$ & 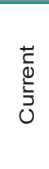 \\
\hline
\end{tabular}

